\title{
Penile Fracture at the Department of Urology and Andrology, University Hospital, Brazzaville
}

\author{
Anani Wencesl Séverin Odzébé*, Roland Bertille Banga Mouss, Aristide Stève Ondziel Opara, \\ Joseph Junior Damba, Armel Melvin Atipo Ondongo, Aucloz Mouzenzo, Prosper Alain Bouya
}

Department of Urology and Andrology, University Hospital, Brazzaville, Republic of the Congo

Email: *odzebe_s@yahoo.fr

How to cite this paper: Odzébé, A.W.S., Mouss, R.B.B., Opara, A.S.O., Damba, J.J., Ondongo, A.M.A., Mouzenzo, A. and Bouya, P.A. (2019) Penile Fracture at the Department of Urology and Andrology, University Hospital, Brazzaville. Open Journal of Urology, 9, 195-200.

https://doi.org/10.4236/oju.2019.912022

Received: January 28, 2016

Accepted: December 20, 2019

Published: December 23, 2019

Copyright $\odot 2019$ by author(s) and Scientific Research Publishing Inc. This work is licensed under the Creative Commons Attribution International License (CC BY 4.0).

http://creativecommons.org/licenses/by/4.0/

\begin{abstract}
Objective: The objectives of this study, was to analyze epidemiological diagnosis, therapeutic option and evolutionary aspects. Materials and methods: This is a retrospective study regarding clinical data of nine penile fracture patients who have been admitted in the department of urology (university hospital, Brazzaville) from January 2006 to December 2018. The study parameters were: epidemiological, diagnosis, operative details, outcomes after treatment, and sexual disorders. Results: The mean age was $46.3 \pm 14$ years, ranged from 25 to 73 years. The etiology of penile fracture was coitus in 5 cases, masturbation in 3 cases and rolling of the penis on the bed in one case. 8 patients were managed surgically. The complications noticed in the postoperative period and during the follow-up visits were penile curvature in 2 cases, and erectyl dysfunction in 2 cases. Conclusion: The diagnosis of penile fracture remains clinic. Immediate surgical management is necessary for good functional result.
\end{abstract}

\section{Keywords}

Penile Fracture, Diagnosis, Treatment, Congo

\section{Introduction}

Penile fracture is a urological emergency [1]. Penile fracture is defined as a traumatic rupture of the tunica albuginea of the corpora cavernosa with or without the corpus spongiosum, secondary to blunt trauma of an erect penis, a resultant corporal defect caused by trauma to the erect penis [2] [3]. Estimated incidence of penile fracture is about 500 - 660 cases per year in the USA [4]. Sexual intercourse, masturbation, forced penile manipulation, rolling over in bed onto the erect penis are considered common causes of this traumatism. Ac- 
cording on a meta-analysis obtained from 58 studies across 26 different countries, its incidence and etiology vary according to geographical region, patterns of sexual behavior, marital status, and culture [5]. Reporting of concurrent urethral injury and long-term complications varies between various regions and countries. Presently, data pertaining to this condition are available from the middle East, Europe, North Africa, as well as North and south America. However, very few studies and those too with a limited number of patients have been reported from the population of East or Southeast Asia [5]. It is the same as our first study, which we reported only 4 cases [6]. The aim of this study was to describe the epidemiological diagnosis and therapeutic characteristics of penile fracture in our department of urology and andrology.

Penile fracture occurs when the erect penis is forcibly bent against resistance leading to a rupture of the corpora cavernosa [7]. The mechanism of penile fracture is coital injury or masturbation [6]. Direct injuries are less frequent [8] [9]. The objectives of this study were to analyze epidemiological diagnosis, therapeutic option and evolutionary aspects of penile fracture in the department of Urology and Andrology.

\section{Material and Methods}

It was a retrospective study, from January 2006 to December 2018, at the department of urology and andrology, university hospital of Brazzaville. This study concerned 9 patients with a diagnosis of penile fracture. The diagnosis of penile fracture was made by clinic only. Any invasive procedure was made. Surgical treatment was standard procedure, by subcoronal degloving incision in the penile skin, a careful examination of the tunica, corpora, and the urethra to record the extent of the injury followed by evacuation of hematoma, and the repair of the tear with slowly absorbing suture was done with vicryl 4 '0.

The study parameters were: epidemiological, diagnosis, operative details, and outcomes after treatment, and sexual disorders. Patients were followed up at one, three and six months after the surgery. The mean period of survey was 23,3 months, ranged from 1 month to 4 years.

\section{Results}

During the period of study, 9 patients were managed at the department of urology and andrology for penile fracture. The mean age was $46.3 \pm 14$ years, ranged from 25 to 73 years. The etiology of penile fracture was coitus in 5 cases, masturbation in 3 cases and rolling of the penis on the bed in one case. Five patients were married, and 4 were singles. The average time of consultation was 22.5 hours, range from 50 minutes to 2 weeks.

The presenting complaint were rapid detumescence during erection, penile swelling, penile dolor, and hematoma and binding (Figure 1) in 8 cases. One patient came for penile curvature. All patients described an audible sudden cracking or snapping sound. 
The location of penile fracture was at the proximal third of the penis in 5 cases, at the average third in 3 cases and in distal third in 1 case. The right corpora cavernosa concerned 6 cases, and the left corpora cavernosa 3 cases. There was not injury of urethra.

Eight patients were managed surgically (Figure 2), and 1 patient with medical treatment (administration of an anti inflammatory drug and antalgic).

The complications noticed in the postoperative period and during the follow-up visits were penile curvature in 2 cases, and erectil dysfunction in 2 cases.

\section{Discussion}

In 1924, Malis and Zur described the first case of penile fracture [10]. Penile fracture is regarded as a relatively rare injury. The incidence of this injury is likely underreported in the world medical literature [11]. The incidence of penile fracture has increased. The true incidence of penile fracture is not known because it is under-reported or hidden probably because of social embarrassment and sociocultural characteristics [12]. Nine patients were seen within 9 years in this work. Twenty one cases were reported in 8 years by Ekeke and Eke in Nigeria [13]. Ouatarra Z, reported 3 cases in 2 months in the department of urology at Gabriel Touré hospital, in Mali [14]. In India twenty patients with penile fracture were reported from November 2012 and November 2014 [15].

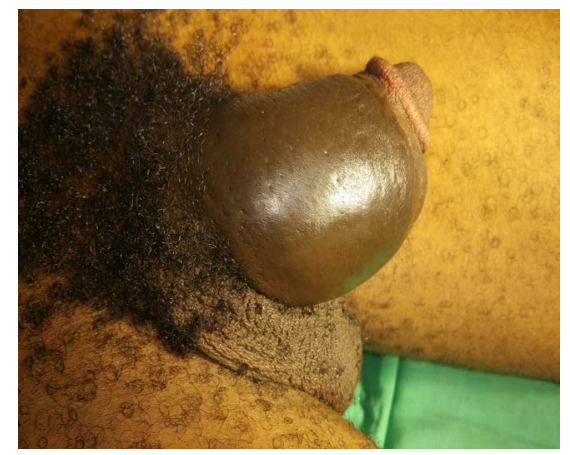

Figure 1. Hematoma and bending of the penis in penile fracture.

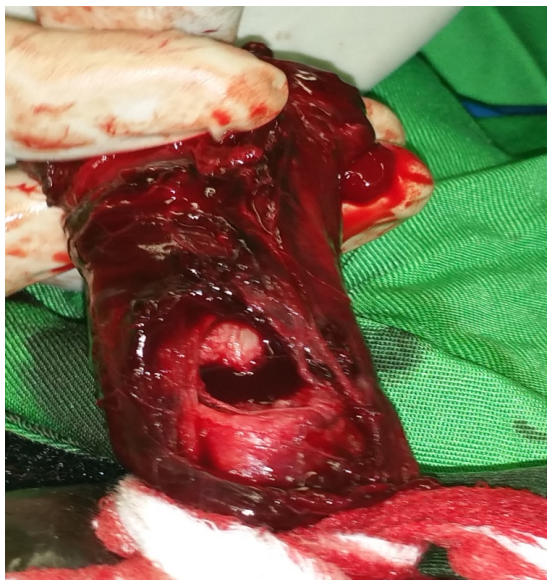

Figure 2. Rupture of corpocavernosa in penile fracture. 
Although it is initially regarded as a relatively rare injury, the actual frequency is not as rare as has been claimed [11]. In the Middle Eastern and Central Asian countries, 1663 cases of penile fracture were reported within the period of 2003 and 2014 [16]. In this study, the major etiology of penile fracture was coitus. The etiology of penile fracture has long been known to differ among various geographic areas. In the United States, like in this study, the majority of cases result from sexual intercourse, usually from thrusting the erect penis against the pubis symphysis. But, in the Mediterranean and Middle Eastern countries manual bending of the penis during erection was the major cause of penile fracture [17]. This is attributed to cultural beliefs or to lack of sexual education in this region as evidence by the widespread practice of "Taqaandan," forceful application of pressure to hide the erect penis, in countries of the middle east [18].

Diagnosis of penile fracture is based on clinical presentation [6] [19] [20]. Additional examinations such as Ultrasonography and MRI can be used for diagnostic confirmation [20] [21]. In the present study, the diagnosis of penile fracture was made by clinical presentation in all cases. In Middle East and Central Asia regions, the diagnosis of penile fracture was made by clinical presentation in 1629 (91.7\%) out of 1663 cases [16]. Penile Fracture may be associated with the rupture of corpus spongiosum in $10 \%-22 \%$ [22]. The incidence of urethral injury is significantly higher in the United States and Europe (20\%), than Eastern word countries and Mediterranean regions (3\%) [23].

Preoperative radiographic investigations such as urethrogram were unnecessary for suspicious urethral involvement in penile fracture cases [24] in Tunisia, this association was reported in 1, 6\% [20].

In this study, 8 patients were managed surgically, and one patient conservatively. Early surgical treatment is associated with a low incidence of late complications [20]. Several studies demonstrated that long-term complications were decreased to as low as $1 \%$ to patients treated surgically. In the last 10 years, conservative treatment has been abandoned because of associated complications, which include hematoma, abscess formation, severe penile angulation, arterial-venous fistulas, and most importantly erectyl dysfunction [6] [22] [23]. On long-term follow-up studies, most patients were able to maintain their erectile function without penile curvature or deformation after immediate surgery [25]. Due to early recovery and short hospital stay after surgery, Penbegul and al. confirmed that patients treated surgically have no evidence of depression or anxiety following penile fracture [26]. Complications such as erectile dysfunction, penile curvature, palpable nodules and painful erection and/or intercourse have been shown to be significantly higher in patients managed conservatively.

\section{Conclusion}

Penile fracture is a urological emergency. Delay in presentation is mainly due to fear and embarrassment. Mechanism of injury depends on socio cultural characteristic, and the principal etiology is coitus. Surgery is the treatment of choice. 
Early intervention gives better outcome.

\section{Conflicts of Interest}

The authors declare no conflicts of interest regarding the publication of this paper.

\section{References}

[1] Sinha Mahapatra, R.K., Prasad Ray, R., Mishra, S. and Kumar Pal, D. (2014) Urethrocutaneous Fistula Following Fracture Penis. Urology Annals, 6, 392-394.

https://doi.org/10.4103/0974-7796.141015

[2] Bali, R.S., Arsha, A., Mushtaque, M., Nabi, S. and Bhat, R.A. (2013) Penile Fracture: Experience from a Third World Country. Advances in Urology, 2013, Article ID: 708362. https://doi.org/10.1155/2013/708362

[3] Kominsky, H., Beebe, S., Shah, N. and Jenkins, L.C. (2019) Surgical Reconstruction for Penile Fracture: A Systematic Review. International Journal of Impotence Research. https://doi.org/10.1038/s41443-019-0212-1

[4] Aaronson, D.S. and Shindel, A.W. (2010) U.S. National Statistics on Penile Fracture. The Journal of Sexual Medicine, 7, 3226. https://doi.org/10.1111/j.1743-6109.2010.01879.x

[5] Amer, T., Wilson, R., Chlosta, P., Al Buheissi, S., Qazi, H., et al. (2016) Penile Fracture: A Meta-Analysis. Urologia Internationalis, 96, 315-329. https://doi.org/10.1159/000444884

[6] Bouya, P.A. (2005) Penile Fracture: Report of 4 Cases. Progres en Urologie, 15, 742-744.

[7] Boncher, N.A., Vricella, G.J., Jankowski, J.T., Ponsky, L.E. and Cherullo, E.E. (2010) Penile Fracture with Associated Urethral Rupture. Case Reports in Medicine, 2010, Article ID: 791948. https://doi.org/10.1155/2010/791948

[8] Mc Aninch, J.W. and Santucci, R.A. (2012) Genitourinary Trauma. In: Walsh, P.C., Retik, A.B., Vaughan, E.D., et al., Eds., CampbelP s Urology, Volume 4, 10th Edition, WB Saunders, Philadelphia, PA.

[9] Martín Hernández, M., Fontana Portella, P., Pérez González, S., Moreno Valle, J.A. and de la Peña Barthel, J.J. (2014) Traumatic Rupture of the Corpus Cavernosum: Surgical Management and Clinical Outcomes. A 30 Years Review. Central European Journal of Urology, 67, 88-92. https://doi.org/10.5173/ceju.2014.01.art20

[10] Malis, J. and Zur, K. (1924) Der fractura Penis. Archiv fur Klinische Chirurgie, 129, 651.

[11] Cendron, M, Whitmore, K.E., Carpiniello, V., Kurzweil, S.J., Hanno, P.M., Snyder, H.M., et al. (1990) Traumatic Rupture of the Corpus Cavernosum: Evaluation and Management. Journal of Urology, 144, 987-991. https://doi.org/10.1016/S0022-5347(17)39642-8

[12] Wani, I. (2008) Management of Penile Fracture. Oman Medical Journal, 23, 162-165.

[13] Ekeke, O.N. and Eke, N. (2014) Fracture of the Penis in The Niger Delta Region of Nigeria. Journal of the West African College of Surgeons, 4, 1-19.

[14] Ouattara, Z., Traor, S.I., Coulibaly, M.T., Diarra, M.Z., Ouattara, A.Z., Sangar, Y. and Demb, L.O. (2013) Fracture of Penis: Diagnosis and Treatment in the Gabriel Touré Hospital Urology. Mali Medical, 27, 37-39. 
[15] Mahapatra, R.S., Kundu, A.K. and Pal, D.K. (2015) Penile Fracture: Our Experience in a Tertiary Care Hospital. The World Journal of Men's Health, 33, 95-102. https://doi.org/10.5534/wjmh.2015.33.2.95

[16] Majzoub, A.A., Canguven, O. and Raidh, T.A. (2015) Alteration in the Etiology of Penile Fracture in the Middle East and Central Asia Regions in the Last Decade; A Literature Review. Urology Annals, 7, 284-288.

[17] Zargooshi, J. (2002) Penile Fracture in Kermanshah, Iran: The Long-Term Results of Surgical Treatment. BJU International, 89, 890-894. https://doi.org/10.1046/j.1464-410X.2002.02745.x

[18] Zargooshi, J. (2009) Sexual Function and Tunica Albuginea Wound Healing Following Penile Fracture: An 18-Year Follow-up Study of 352 Patients from Kermanshah, Iran. The Journal of Sexual Medicine, 6, 1141-1150. https://doi.org/10.1111/j.1743-6109.2008.01117.x

[19] Al Ansari, A., Talib, R.A., Shamsodini, A., Hayati, A., Canguven, O. and Al Naimi, A. (2013) Which Is Guilty in Self-Induced Penile Fractures: Marital Status, Culture or Geographic Region? A Case Series and Literature Review. International Journal of Impotence Research, 25, 221-223. https://doi.org/10.1038/ijir.2013.16

[20] El Atat, R., Sfaxi, M.R., Amine, D., Ayed, M., Moueli, S.B., Chebil, M. and Zmerl, S. (2008) Fracture of the Penis: Management and Long-Term Results of Surgical Treatment. Experience in 300 Cases. The Journal of Trauma: Injury, Infection, and Critical Care, 64, 121-125. https://doi.org/10.1097/TA.0b013e31803428b3

[21] Lindquist, C.M., Nikolaidis, P., Mittal, P.K. and Miller, F.H. (2019) MRI of the Penis. Abdominal Radiology. https://doi.org/10.1007/s00261-019-02301-y

[22] Lynch, T.H., Martínez-Piñeiro, L., Plas, E., Serafetinides, E., Türkeri, L., Santucci, R.A., et al. (2005) EAU Guidelines on Urological Trauma. European Urology, 47, 1-15. https://doi.org/10.1016/j.eururo.2004.07.028

[23] Yapanoglu, T., Aksoy, Y., Adanur, S., Kabadayi, B., Ozturk, G. and Ozbey, I. (2009) Seventeen Years' Experience of Penile Fracture: Conservative vs. Surgical Treatment. The Journal of Sexual Medicine, 6, 2058-2063. https://doi.org/10.1111/j.1743-6109.2009.01296.x

[24] Derouiche, A., Belhaj, K., Hentati, H., Hafsia, G., Slama, M.R. and Chebil, M. (2008) Management of Penile Fractures Complicated by Urethral Rupture. International Journal of Impotence Research, 20, 111-114. https://doi.org/10.1038/sj.ijir.3901599

[25] Gamal, W.M., Osman, M.M., Hammady, A., Aldahshoury, M.Z., Hussein, M.M. and Saleem, M. (2011) Penile Fracture: Long-Term Results of Surgical and Conservative Management. The Journal of Trauma: Injury, Infection, and Critical Care, 71, 491-493. https://doi.org/10.1097/TA.0b013e3182093113

[26] Penbegul, N., Bez, Y., Atar, M., Bozkurt, Y., Sancaktutar, A.A., Soylemez, H., et al. (2012) No Evidence of Depression, Anxiety, and Sexual Dysfunction Following Penile Fracture. International Journal of Impotence Research, 24, 26-30. https://doi.org/10.1038/ijir.2011.42 